\title{
Discussion on the Reform of Curriculum Group of Electrical Fundamental Courses
}

\author{
Zhihong Xiao \\ School of Electronic Engineering \\ Xi'an Shiyou University \\ Xi'an, China
}

\begin{abstract}
The curriculum group of electrical fundamental courses for electrical major in Colleges and Universities includes "Elementary Circuit Analysis", "Signal and System", "Digital Signal Processing","Analog Electronic Technology" and "Digital Electronic Technology" etc. It plays a very important role in expanding student's knowledge and improving their practice ability According to the features of the electrical basic courses and the needs of personnel training for electrical major in Colleges and Universities, a new idea for the reform of the basic course of electrical professional technology is introduced in this paper, which including teaching system, teaching contents, and laboratory construction. It can break the old relatively independent teaching mode and build a new teaching system so as to make students have solid academic foundation, cultivate their innovative consciousness and innovative ability.
\end{abstract}

Keywords-Electrical foundation courses; The curriculum group; Electrical major; Teaching reform

\section{INTRODUCTION}

"Elementary Circuit Analysis", "Signal and System", "Digital Signal Processing","Analog Electronic Technology" and "Digital Electronic Technology" are very important professional foundation courses for electrical majors, They are both theoretical and practical courses and are the basis for follow-up professional courses. A total of 10 electrical majors in our school have set up these courses. The quality of these courses directly affects the professional level and comprehensive quality of students.

In recent years, we have carried out corresponding curriculum construction and teaching reforms for these courses, and achieved certain results. But there are still some problems, such as excessive repetition of some knowledge, the transition between courses is not reasonable enough, the teaching content and teaching methods are relatively isolated and the knowledge obtained by students is not complete enough to establish a systematic concept and overall awareness. Therefore, the partial optimization reform of each course is absolutely necessary for a period of time. However, from the perspective of the overall situation of talent training, if there is a lack of integrated curriculum reform, it will inevitably lead to an inefficient situation, which is not conducive to the cultivation of students' comprehensive quality. Therefore, in order to cultivate applied talents with innovative ability and high comprehensive quality, it is necessary to carry out a series of overall optimization reforms on these basic courses of professional technology, clarify the context between courses, build an overall knowledge framework, and form a complete system.

The curriculum group is to group together different courses with relevance or certain characteristics to form a "group" to teach systematically [1-3]. The knowledge points of the above six professional basic courses permeate each other and are complementary, and they are the public professional foundations of many electric majors [4-5]. Therefore, it is suitable for them to form a curriculum group and become an organic whole.

\section{CONTENT OF CURRICULUM GROUP CONSTRUCTION}

The content of course group construction includes the integration of teaching content, the reform of teaching methods, the establishment of resource sharing library and the reform of practice links, etc.

\section{A. Relationship between courses in the curriculum group}

The curriculum group of electrical fundamental courses Consists of the above six courses.

"Elementary Circuit Analysis" is the earliest course offered in this course group. It is the first step of students to be exposed electronic technology and signal processing technology. It is the basis of other courses in the course group. The major contents are circuit basic concepts, laws and circuit theorem, resistive circuit analysis techniques, time domain analysis of dynamic circuit, sinusoidal stable circuit analysis, mutual inductance and ideal transformer, etc.

"Signal and System" mainly discusses the characteristic of deterministic signal and linear time-invariant (LTI) system. The course involves time-domain analysis , frequency-domain analysis and complex frequency-domain analysis of both continuous and discrete signal and system.

"Analog Electronic Technology" mainly discusses the performance of all kinds of semiconductors and its applications and introduces analysis and design methods of basic electronic circuits. This course is conducted simultaneously with "signal and system". The two courses have different analysis methods for some of the same systems.

"Digital Electronic Technology" contains the analysis and design of combinational circuits and sequential circuits. It also contains the typical parameters and characteristics of the TTL, CMOS, Mono-stable, Multivibrator, Schmitt trigger, Semi- 
conductor Memory and the basic principles of programmable logic devices (PLD), etc.

"Digital Signal Processing" is the study of signals in a digital or a sequence with sign representation and the processing methods of these signals to extract some valuable information using digital computers. Its first professional course are "signal and system" and "Digital Electronic Technology"

The relationship between the courses in the curriculum group is shown in Fig 1.

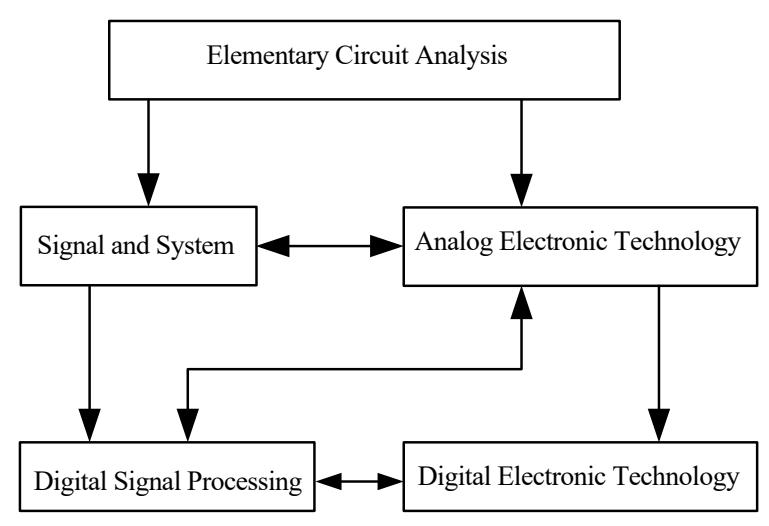

Fig. 1 The relationship between the courses

\section{B. Integration of Teaching Contents and Reform of Teaching Methods}

The primary content of the curriculum group construction is to optimize and integrate the teaching content of each course, add, delete, and remove duplicate content from the relevant course content, share resources, and organize the mutual connection and mutual penetration between the courses. Build a holistic framework to form a new teaching system with clear goals and tight connections. For example, the " Elementary Circuit Analysis " and "Signal and System" are unified to allow students to establish the concept of signals and systems early. In the course of teaching " Elementary Circuit Analysis ", the teacher should guide the students to integrate the two courses organically under the general concept of circuit, signal and system in order to understand the role and connection of various analysis methods. Let students establish the concept of transform domain analysis early, Let the students understand that the phasor of the sine function is the transformation domain description of the sine function. The Laplace transform analysis method is introduced in the second-order dynamic circuit analysis and compared with the classical time domain analysis method.

When teaching the "Signal and System" course, It is also possible to use the circuit examples of its pre-requisite course " Elementary Circuit Analysis " and parallel course " Analog Electronic Technology " to explain the analysis methods of the time, frequency, and complex frequency domains of the " Signal and System " course. Such a comparative learning method can stimulate students' ability to comprehensively apply what they have learned to observe, analyze, and explore.

With the development of electronic technology, the content of the teaching of " Analog Electronic Technology " and "Digital Electronic Technology" should be updated accordingly. At the same time, the system analysis concept of "Signal and System" and "Digital Signal Processing" must be introduced into the teaching of these two courses.

Introducing project-based teaching into the curriculum group teaching, combining theory with practice through practical projects, students 'interest and comprehensive analytical ability are well stimulated, and the content of subsequent courses is brought forward early. For example, after explaining the transient response of the first-order circuit in the " Elementary Circuit Analysis " course, let the students design the reset circuit of the single-chip microcomputer, which the relevant technical specifications are given. The student is allowed to form a team of two or three people to complete the project design, simulation, and design report.

\section{Establishment of a Resource Sharing Library}

The courses in the course group are very closely connected. Therefore, it is necessary to establish a public teaching resource library. The teachers of in each course in the course group jointly design teaching cases and thinking exercises, and set up penetrating teaching cases for closely related courses. Different courses use different methods and different perspectives to analyze the same case.

\section{Reform of Practice}

The six courses in the course group are all highly theoretical and practical courses, so the reform of practical links is very important. The following are the measures to reform the practical link.

- Increase the number of simulation experiments, maintain the consistency of course group simulation experiments, and put "Multisim", "MATLAB", and "LabVIEW" throughout the courses of the course group.

- The number of comprehensive design experiments is increased, and the boundaries of experimental teaching in each course as well as the boundaries of software experiments and hardware experiments are diluted. It is not enough for some courses to be experimented only in a "virtual" environment, which makes it difficult for students to establish a true system concept and understand the characteristics of signals and systems. We make full use of the students 'knowledge in "circuit analysis", "analog electronic technology" and "Digital Electronic Technology", In some experiments, students are allowed to design signal processing circuits with the same function after software simulation. The circuit test results are compared with the software test results by students. Such reforms can not only stimulate students 'interest in learning, but also help students understand and master the basic principles of the course, basic analysis 
methods, and the ability to use the knowledge learned to solve practical problems. The sampling theorem experiment of the signal and system course is described below. After the experiment is completed by the application simulation software, the students can build a hardware circuit to sample and reconstruct the signal, and compare the experimental results. Practice has proved hat students not only understand the sampling theorem, but also understand the signal processing system and their ability to do it. Fig. 2 is the results of MATLAB simulation after undersampling the sine signal. Fig. 3 shows the experimental wave map of the circuit reconstructed after undersampling of the sine signal.
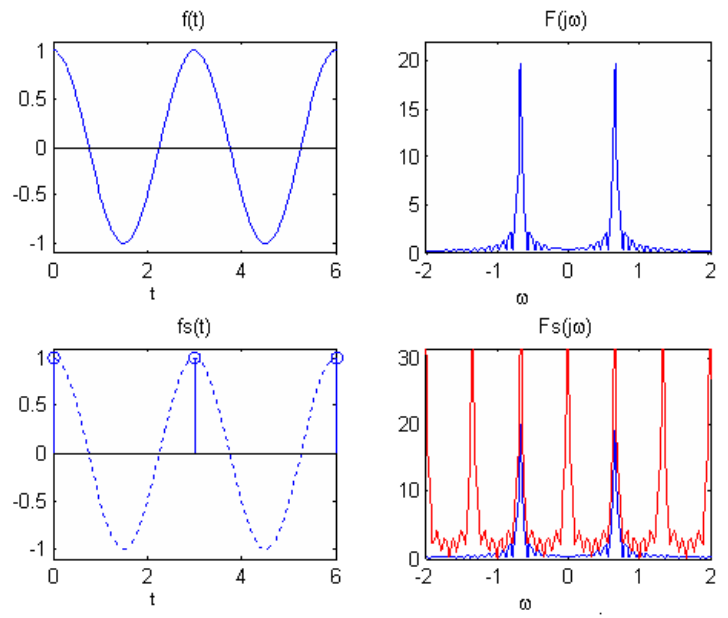

Fig. 2 The Waveform diagram of matlab experiment

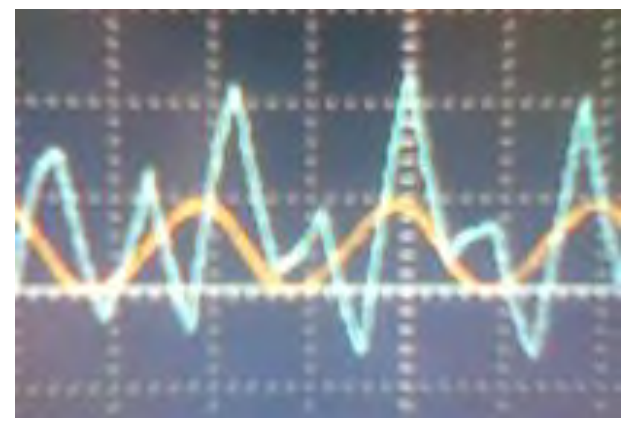

Fig. 3 The Waveform diagram of hardware circuit test

- Increase the number of integrated digital signal processing experiments. This comprehensive experiment is not just software programming. It requires DSP peripheral circuits, signal acquisition circuit, driver circuits and digital signal processors to form a system. This kind of experiment is the comprehensive application of circuit analysis, electronic technology, signal and system, digital signal processing and computer application registration course knowledge. which has greatly improved the students' practical ability, innovative spirit and comprehensive quality.
- Encourage students to participate in various innovation and entrepreneurship activities. Undergraduate Innovation and Entrepreneurship Training Program which Divided into national, provincial, school-level and other levels is an important part of the Teaching Reform Project by Ministry of Education since 2010 [6-7]. Students are free to organize teams and complete innovative research project design, preparation and implementation of the project study conditions, the researchers report writing, the academic communication and so on autonomously. It can consolidate and deepen students 'understanding of the theoretical knowledge, enable students to master the basic methods of scientific research and cultivate students' innovative consciousness and comprehensive practical ability.

\section{CONCLUSION}

In the course group construction, we have optimized the teaching content of each course, improved the teaching methods, strengthened the concept of the system, and made the teaching arrangement and content convergence more reasonable. Practice has proved that students 'learning ability, comprehensive ability, innovation ability and engineering practice ability have been improved.

\section{ACKNOWLEDGMENT}

The author would like to express her gratitude to the members participating in course cluster development. Thanks are also to Xi'an Shiyou University and all colleagues who previously provide support.

\section{REFERENCES}

[1] Iqbal and Tariq, "Cooperative learning in lectures of an advanced electrical engineering course", International Journal of Electrical Engineering Education, vol. 49, pp. 38-39, January 2012,

[2] Guo Yu, Li Rui and Wang Xiaodan, "Research and Practice of Multidimensional Assessment System of "Three Electricity" Basic Course for Engineering", Heilongjiang Education(Higher Education Research \& Appraisal), vol. 12, pp. 54-55, June 2014.

[3] Dong zhanqi, " Discussion on the Integration Teaching of Telecommunications Courses", University Education, vol. 12, pp. 39-41, December 2017.

[4] Zhang Ziyan, "On the Teaching Reform of "Circuit Analysis" from the Perspective of Curriculum Group", Electronics World, vol. 12, pp. 38-39, October 2018

[5] Zhang Wei, Zhang Hong and Yin weichun, "Research on Comprehensive Experimental Design of "Signal Analysis and Processing" Course Group", Science \& Technology Information, vol. 29, pp. 133-134, October 2016.

[6] Wang Hailiang, Ren quanchang, Yu Yangand Song Hao, "The implementation experience of National college students innovative entrepreneurial training program", China Electric Power Education, vol. 25, pp. 206-207, May 2013.

[7] Information on http://www.moe.gov.cn/publicfiles/business/htmlfiles/moe/s5972/20140 4/xxgk_166881.html. 